University of Nebraska - Lincoln

DigitalCommons@University of Nebraska - Lincoln

Posters, Addresses, \& Presentations from CYFS Children, Youth, Families \& Schools, Nebraska

Center for Research on

August 2006

\title{
CBC Through a New Lens: Exploring Individual Outcomes in Groups
}

\author{
Susan M. Sheridan \\ University of Nebraska - Lincoln, ssheridan2@unl.edu \\ Todd A. Glover \\ University of Nebraska - Lincoln, tglover2@unl.edu \\ Kathryn A. Black \\ University of Nebraska - Lincoln \\ Stanley A. Garbacz \\ University of Nebraska - Lincoln, agarbacz2@unl.edu \\ Amanda L. Witte \\ University of Nebraska - Lincoln, awitte2@unl.edu \\ See next page for additional authors
}

Follow this and additional works at: https://digitalcommons.unl.edu/cyfsposters

Part of the Pre-Elementary, Early Childhood, Kindergarten Teacher Education Commons

Sheridan, Susan M.; Glover, Todd A.; Black, Kathryn A.; Garbacz, Stanley A.; Witte, Amanda L.; Swanger, Michelle S.; Johnsen, Lynae A.; and Meints, Christina A., "CBC Through a New Lens: Exploring Individual Outcomes in Groups" (2006). Posters, Addresses, \& Presentations from CYFS. 5.

https://digitalcommons.unl.edu/cyfsposters/5

This Article is brought to you for free and open access by the Children, Youth, Families \& Schools, Nebraska Center for Research on at DigitalCommons@University of Nebraska - Lincoln. It has been accepted for inclusion in Posters, Addresses, \& Presentations from CYFS by an authorized administrator of DigitalCommons@University of Nebraska Lincoln. 


\section{Authors}

Susan M. Sheridan, Todd A. Glover, Kathryn A. Black, Stanley A. Garbacz, Amanda L. Witte, Michelle S. Swanger, Lynae A. Johnsen, and Christina A. Meints 


\section{Nebraska

Introduction
- Untreated behavior problems in elementary school students can result in a
trajectory of negative life outcomes, which include more failed courses, lower trajectory of negative life outcomes, which include more failed courses, lower grade
point averages, increased absenteeism, and higher retention rates compared to other point averages, increased absen
students (Wagner et al., 1993).

- Family-school partnerships and parental involvement in interventions and educational programs positively correlate with favorable outcomes for students

families, and teachers (e.g., Grolnick \& Slowiaczek, 1994). - Conjoint Behavioral Consultation (CBC; Sheridan, Kratochwill, \& Bergan, 1996;
Sheridan \& Kratochwill in press) maintins promise as an evidence-based model for Sheridan \& Kratochwill, in press) maintains promise as an evidence-based
increasing ongoing, collaborative family-school interactions (Guli, 2005).

- Conducted with parents and teachers together, as joint consultees

- Concerns are identified, analyzed, and addressed through collaborative interactions between the consultees and guidance from a consultant.

- Modified recently to (a) provide CBC in a small, group format (i.e., the families of $2-3$ students and their teacher) and (b) assure intervention implementation integrity and appropriate levels of consultant support

- A large-scale, randomized clinical trial is being conducted to investigate the effectiveness of the modified $C B C$ process and to expand upon the single-case
experimental research on $C B C$ as a promising, evidence-based consultation model. - The current study investigated preliminary findings from a subset of the clinical

\section{Purpose and Research Questions}

- To evaluate the effectiveness of the modified CBC process on a case level throug mple of the larger, clinical trial Question 1: What are the immediate effects of the modified CBC process on

Question 2: Do teachers and parents find this method of intervention acceptable? Methods

Participants and Setting
Table 1

Table 1
Demographic Characteristics of Student Participants

\begin{tabular}{|c|c|c|c|c|c|}
\hline Sudater & Tagagen nedd & Classomam & Gialde & Age & Eituriciy \\
\hline Astratum & 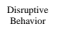 & A & 1 & 8 & $\begin{array}{c}\text { whinger } \\
\text { hime }\end{array}$ \\
\hline Thomas & 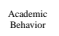 & $A$ & 1 & 7 & 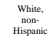 \\
\hline Josstyp & 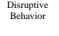 & B & 3 & 10 & 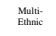 \\
\hline Kevin & 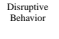 & в & 3 & 10 & 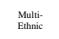 \\
\hline $\mathrm{lmm}$ & 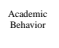 & c & 3 & 8 & 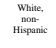 \\
\hline & 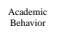 & c & 3 & 8 & 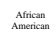 \\
\hline
\end{tabular}

Table 2
Demograp

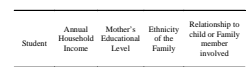

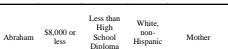

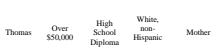

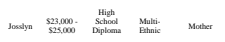

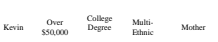

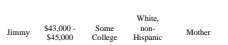

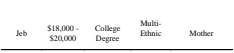

- Teachers involved in CBC were all White, non-Hispanic females with an average of 12.3 years of teaching experience (SD 12.6 ; range $=1-26$ ) and an participants through teacher report on the Systematic Screening for Behavior litional follow-up

- Consultation sessions took place in the classrooms of schools in a Midwester public school district; child participants wers - School 1 ( Classroom A): 369 students PreK-5; 14\% students of color; 40\%

- School 2 (Classroom B): 257 students K-5; 54\% students of color, $62 \%$ - School 3 (Classroom C): 499 students K-5; 10\% students of color; 14\% eligible for freesreduced meals

Procedures
CBC stages:

Needs Identification and Needs Analysis (Building on Strengths)

- Review strengths of student, family, and school

- Prioritize 1-2 target behaviors per student

- Identify and define needs, settings, and goad

- Discuss ways to gather information

- Discuss and select strategies for change

Plan Development (Planning for Success)

Objectives

- Discuss information collected by parents and teachers about identified

behavior(s)

- Develop a plan to address student needs

- Discuss ways to support the plan at home and school

- Continue to gather information

Plan Evaluation (Checking and Reconnecting)

bjectives

- Discuss progress made toward goals

- Evaluate the plan(s)
Measures and Data Collection

Performance and behavioral data were collected daily in the classrooms by teachers utilizes a Likert-type scale, range $1-5$ ( $1=$ worst outcome, $3=$ typical outcome, and $5=$ best possible outcome) to measure teacher ratings of student performance.
- Frequency or duration of disunptive behaviors were reported on daily report forms.

Acceptability data were collected using the Behavioral Intervention Scale-Revised (BIRS-R; Elliott \& Von Brock Treuting, 1991) upon completion of the Plan Evaluation stage.

Design
- Amultiple probe across participants design was used
- Data were collected simultaneously across participan

- Data were collected simultaneously across participants

- Experimental control was established throug

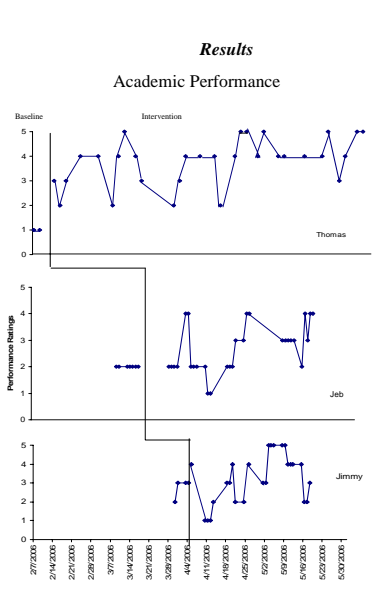

Disrrutive Behavior

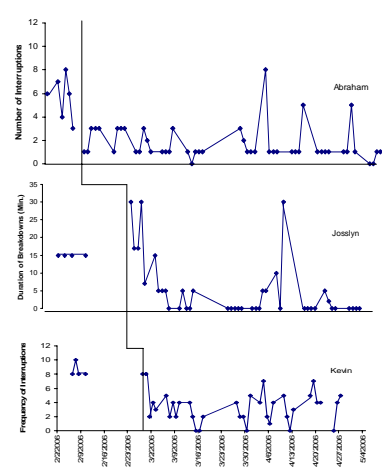

Table 3

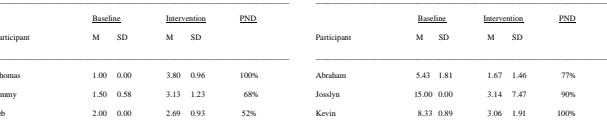

Table 5

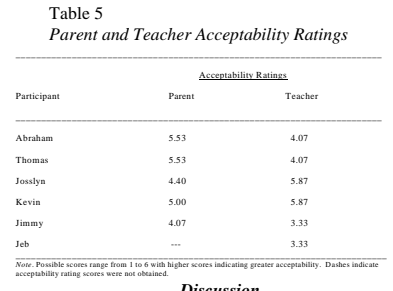

Discussion
What are the immediate effects of the modified CBC process on externalizing behaviors

- Ratings and behavioral data appear to indicate that the modified $\mathrm{CBC}$ process had positive effects on both academic and dissuptive behaviors
preliminary support to modified, group $C B C$ as effective

- All participants improved their performance in the desired direction

- Moderate to high PND suggest intervention effects in all participants with the
exception of Jeb

- More positive effects were demonstrated in students with disruptive behavior needs,

- A greater degree of objectivity in behavioral target needs (e.g., interruptions) than in academic performance behaviors (e.g, academic engagement)
- Frequency and durtion rating

Do teachers and parents find this method of intervention acceptable?

- The majority of parents and teachers reported high rates of acceptability. - Parents and teachers previously rated traditional CBC as an acceptable form of service
delivery (Sheridan, Eagle, Cowan, \& Mickelson, 2001); findings from the current study corroborate this, suggesting the majority of parents and teachers rate group CBC similar

- Performance ratings and behavioral data were collected by teachers, rather than

作 Future Directions
- Using data collect

- Collecting intervention integrity data across all student participants

- Collecting and analyzing outcome data in home settings

- Understanding components of the CBC process parents and teachers find acceptable
and unacceptable 